\title{
Predictive Value of Albumin and Neutrophil Combined Prognostic Grade in Advanced Gastric Cancer Patients Treated With anti-PD-1 Therapy
}

\section{Yuting Pan}

Medical School of Chinese PLA: Chinese PLA General Hospital

\section{ZhiKuan Wang}

Chinese PLA General Hospital

Guanghai Dai ( $\nabla$ dgh301307@126.com )

Chinese PLA General Hospital https://orcid.org/0000-0001-8839-6369

\section{Research}

Keywords: immunotherapy, advanced gastric cancer, albumin, neutrophil, prognosis

Posted Date: November 11th, 2021

DOI: https://doi.org/10.21203/rs.3.rs-1019780/v1

License: (c) (i) This work is licensed under a Creative Commons Attribution 4.0 International License.

Read Full License 


\section{Abstract}

Background The application of immunotherapy is gradually increasing in advanced gastric cancer (AGC), but only some patients could benefit from it. Validated biomarkers can screen out the beneficiaries. The objective of this research is to explore the predictive value of albumin and neutrophil combined prognostic grade (ANPG) in AGC patients receiving immunotherapy.

Methods A total number of 268 AGC patients were included. The cut-off value of albumin was $38 \mathrm{~g} / \mathrm{L}$ obtained by the median value, and neutrophil was $4.16 \mathrm{~g} / \mathrm{L}$ estimated by the average value. The high levels of albumin ( $\geq 38 \mathrm{~g} / \mathrm{L})$ and neutrophil $(\geq 4.16 \mathrm{~g} / \mathrm{L}$ ) were considered to be two risk factors for ANPG. Based on these two risk factors, patients were categorized into 3 groups $邓$ the risk factor number for the "good" group was 0 , for the "intermediate" group was 1, and for the "poor" group was 2.

Results Patients with the good ANPG was related to longer progression free survival (PFS) and overall survival (OS), compared to those with the intermediate and the poor ANPG (5.6 months vs 5.3 months vs 3.4 months, 17.8 months vs 11.8 months vs 8.2 months). The poor group was independently correlated with an over 1.9 times risk of disease progression $(\mathrm{HR}=1.901 ; 95 \% \mathrm{Cl}, 1.314-2.750 ; \mathrm{P}=0.001)$ and an over 2 times risk of death $(\mathrm{HR}=2.003 ; 95 \% \mathrm{Cl}, 1.306-3.072 ; \mathrm{P}=0.001)$ than the good group. The intermediate group was independently correlated with an over 1.3 times risk of disease progression ( $\mathrm{HR}=1.385 ; 95 \% \mathrm{Cl}$, $1.004-1.911 ; \mathrm{P}=0.048)$ and an over 1.4 times risk of death $(\mathrm{HR}=1.484 ; 95 \% \mathrm{Cl}, 1.046-2.106 ; \mathrm{P}=0.027)$ than the good group.

Conclusion Our study verifies, for the first time, that ANPG is an independent factor affecting survival of AGC patients receiving immunotherapy. Patients with the good ANPG could benefit from immunotherapy.

\section{Introduction}

Gastric cancer (GC) is a clinically aggressive gastrointestinal tumors around the world ${ }^{[1]}$. The incidence rate of GC ranks fifth globally and second domestically in China ${ }^{[1]}$. The progress of GC treatment is relatively slow, and the traditional chemotherapy, such as surgery, chemotherapy, and targeted therapy are limited. The emergence of immunotherapy brings new option for GC, but its application in GC is difficult. People have tried both back line and front line, as well as single drug and combinations. The ATTRACTION-2 study confirms the efficacy of nivolumab for the back line of $\mathrm{GC}^{[2,3]}$. The results of the KEYNOTE-061 study were negative, and pembrolizumab failed in the second-line challenge chemotherapy ${ }^{[4-6]}$. The CheckMate 649 study explored that the nivolumab-based first-line immunotherapy was suitable for advanced GC (AGC) ${ }^{[7]}$. Moehler $M$ et al. found that patients treated with combination of nivolumab and chemotherapy showed improved overall survival (OS) benefits, regardless of the expression status of programmed death ligand-1 $(P D-L 1)^{[8]}$. The first result of the KEYNOTE-811 study showed that the combination of pembrolizumab, trastuzumab, and chemotherapy for HER2positive metastatic gastric or gastroesophageal junction cancer ${ }^{[9]}$. However, the current evaluation of biomarkers for immunotherapy is limited, there is a lack of effective biomarker to be used as a prognostic 
factor for AGC patients treated with immune checkpoint inhibitors (ICls ${ }^{[10]}$. In recent years, the expression of $P D-L 1$ and microsatellite steady-state (MSI) in AGC patients can effectively assess the efficacy of immunotherapy ${ }^{[10,11]}$. Peripheral blood inflammatory complex index such as lung immune prognostic index (LIPI), neutrophil-lymphocyte ratio (NLR), platelet-lymphocyte ratio (PLR), and hemoglobin ( $\mathrm{Hb})$ levels had demonstrated a convenient and promising prognostic biomarker for $\mathrm{GC}^{[12-16]}$. However, the highly heterogeneous characteristics of GC may limit the accuracy of a single biomarker for screening immunotherapy benefiting populations. In contrast, the combination of multiple indicators can provide more targeted information for the detection of potential immune benefit subgroups. Albumin and neutrophil combined prognostic grade (ANPG) was a composite biomarker of neutrophil and albumin ${ }^{[17]}$. The high levels of albumin ( $\geq 42.55 \mathrm{~g} / \mathrm{L})$ and neutrophil $(\geq 2.895 \mathrm{~g} / \mathrm{L})$ were considered to be two risk factors for ANPG. Based on these two risk factors, patients were categorized into 3 groups: the risk factor number for the "good" group was 0 , for the "intermediate" group was 1 , and for the "poor" group was $2^{[17]}$. Sun $\mathrm{H}$ et al. found that patients with the good ANPG was independently associated with better prognosis for non-small cell lung cancer (NSCLC) patients ${ }^{[17]}$. However, there is no research on ANPG in immunotherapy of patients with tumor. Thus, we carried out the present study to explore the clinical value of ANPG in predicting prognostic outcomes of AGC patients following ICls treatment.

\section{Materials And Methods}

2.1 Study population All patients involved were diagnosed with GC at stage IV and received ICls treatment in the Senior Department of Oncology, Chinese PLA General Hospital, from December 2014 to May 2021. We set the inclusion criteria as following: 1)patients detected with measurable lesions; 2) patients conducted blood routine and blood biochemistry tests within one week before ICls administration; 3 ) patients continuously received at least two rounds of $\mathrm{ICls}$ treatment. Patients failing to provide imaging data for comparing the efficacy of ICls before and after treatment were excluded. Clinical parameters of patients from their medical records were collected, including smoking history, smoking exposure, sex, age, tumor type, the statu of HER-2 expression, the statu of liver metastasis, response to line before immunotherapy, the statu of pleural fluid, the statu of ascites, the number of metastatic sites, lines of treatment with ICls, ICls agent, immunotherapy scheme, and eastern cooperative oncology group performance status scores (ECOG PS). Meanwhile, we analyzed their blood routine parameters 7 days before implementing immunotherapy to obtain albumin and neutrophil values.

2.2 Treatment regimens Five treatment methods were used in this study, including: ICls monotherapy, ICls combined with chemotherapy, ICls combined with anti-angiogenic therapy, ICls combined with DNAderived humanized monoclonal antibodies (trastuzumab) and chemotherapy, and Cls combined with chemotherapy and anti-angiogenic therapy. The types and doses of ICls were as follows: 1) sintilimab was injected intravenously $200 \mathrm{mg}$ once every 3 weeks; 2) toripalimab was injected intravenously $240 \mathrm{mg}$ once every 3 weeks; 3 ) the recommended dose of pembrolizumab injection for intravenous infusion was a dose of $3 \mathrm{mg} / \mathrm{kg}$, administered once every 3 weeks; 4 ) the recommended dose of nivolumab injection for intravenous infusion was a dose of $2 \mathrm{mg} / \mathrm{kg}$, administered once every 2 weeks. The first imaging 
evaluation of nivolumab was carried out 2-4 weeks after the 3rd intravenous injection, but, the evaluation of toripalimab, sintilimab, and pembrolizumab were carried out 3-5 weeks after the 2 rd intravenous injection. The course of trastuzumab was 3 weeks. For the first course, the dose was $8 \mathrm{mg} / \mathrm{kg}$, applied by intravenous injection for 90 minutes. Starting from the $2 \mathrm{rd}$ course, the dose was lowered to $6 \mathrm{mg} / \mathrm{kg}$. And for the infusion time, if the patients tolerate trastuzumab well in the first course. Anti-angiogenic drugs involve apatinib ( $850 \mathrm{mg}$, orally administrated $30 \mathrm{~min}$ after a meal, once a day), and bevacizumab (5 $\mathrm{mg} / \mathrm{kg}$ body weight, once every two weeks; or $7.5 \mathrm{mg} / \mathrm{kg}$ body weight, once every 3 weeks). The chemotherapy regimens include 1) XELOX regimen: capecitabine $\left(1000 \mathrm{mg} / \mathrm{m}^{2}\right)$ was used 2 times a day orally after breakfast and dinner for 14 consecutive days with 7 days of rest as a treatment cycle. oxaliplatin $\left(130 \mathrm{mg} / \mathrm{m}^{2}\right)$ was added at the first day of each cycle by intravenous injection; 2$)$ SOX regimen: tiggio: (40-60mg) was used 2 times a day orally after breakfast and dinner for 14 consecutive days with 7 days of rest as a treatment cycle. oxaliplatin $\left(130 \mathrm{mg} / \mathrm{m}^{2}\right)$ was added at the first day of each cycle by intravenous injection; 3) DCF regimen: docetaxel $\left(75 \mathrm{mg} / \mathrm{m}^{2}\right)$, cisplatin $\left(75 \mathrm{mg} / \mathrm{m}^{2}\right)$, and fluorouracil $\left(750 \mathrm{mg} / \mathrm{m}^{2}\right)$ were applied by intravenous injection. On the first day of every course, each course lasted 21 days. 4) The combined regimen of irinotecan and oxaliplatin: irinotecan $\left(180 \mathrm{mg} / \mathrm{m}^{2}\right)$ and oxaliplatin $\left(130 \mathrm{mg} / \mathrm{m}^{2}\right)$ were applied by intravenous injection. On the first day of every course, each course lasted 14 days. 5) The combined regimen of irinotecan and raltitrexed: irinotecan $\left(180 \mathrm{mg} / \mathrm{m}^{2}\right)$ and raltitrexed $\left(3 \mathrm{mg} / \mathrm{m}^{2}\right)$ were applied by intravenous injection. On the first day of every course, each course lasted 14 days. 6 ) others. The choice of the above regimens was based on the patient's pathological stage, general health conditions.

2.3 Assessment For efficacy evaluation, the disease control rate(DCR)and the overall response rate (ORR) is termed as the percentage of patients with complete response (CR), partial response (PR) and stable disease (SD) and the percentage of patients with $C R$ and PR, respectively. For prognosis analysis, OS and progression free survival (PFS) are the time from the begining of immunotherapy to death and the time between the onset of ICls and the progression or death of the tumor, respectively.

2.4 Neutrophil, albumin, and ANPG We analyzed the value of neutrophil, and albumin 7 days before implementing immunotherapy. The cut-off value of albumin was estimated by the median value and neutrophil was obtained by the average value. The high levels of albumin ( $\geq$ the median value) and neutrophil ( $\geq$ the average value) were considered to be two risk factors for ANPG. Based on these two risk factors, patients were categorized into 3 groups: the risk factor number for the "good" group was 0 , for the "intermediate" group was 1, and for the "poor" group was 2.

2.5 Statistical analysis SPSS 26.0 software was used to perform all statistical analysis. Datas were summarized as the minimum-maximum range and median for non-normally distributed continuous variables. Datas were reported as percentages and counts for categorical variables. $\chi 2$ or Fisher exact test was carried out to evaluate the relationship between clinical response and ANPG groups of AGC patients. The survival curve was depicted by Kaplan-Meier analysis. Logistic regression models and Cox proportional hazard were applied to assess the prognostic values of ANPG groups for DCR, and survival, respectively. Values of $P$ less than $0.05(p<0.05)$ were considered statistically significant. 


\section{Results}

3.1 Baseline characteristics A total of 268 AGC patients receiving ICls were retrospectively reviewed in the study. The clinical feature of patients were provided below (Table 1). The cut-off value of albumin and neutrophil were $38 \mathrm{~g} / \mathrm{L}$ and $4.16 \mathrm{~g} / \mathrm{L}$, respectilvely. After grouping, the numbers of patients with the good ANPG, with the intermediate ANPG, and with the poor ANPG were ninety five, one hundred and eighteen, and fifty-five. The median age of patients with the good ANPG, the poor ANPG, and the poor ANPG were 56-year-old, 60-year-old, and 59-year-old, respectively. Patients were predominantly male (74.3\%), no history of smoking $(62.3 \%)$, short history of smoking exposure (smoking exposure history is less than or equal to 30 years in $82.1 \%$ of cases), ECOG PS of 0-1 ((94\%), the tumor location of Body/Fundus (41\%), no hepatic metastasis (55.6\%), negative expression of HER-2 (66\%), no pleural fluid (92.9\%), no ascites (75.4\%) and had fewer organ metastasis (the number of metastatic sites of $0-2$ in $75.4 \%$ of cases)

3.2 Treatment characteristics of 268 patients, 175 (65.3\%) patients had previously progressed before using ICls;88 (32.8\%) patients received nivolumab, 36 (13.4\%) patients were treated with pembrolizumab and 144 (53.7\%) patients received other immunotherapy drugs; 143 (53.4\%) patients used the 1 st line ICls ; and $173(64.6 \%)$ patients were recieving the combinated plan of immunotherapy and chemotherapy (Table 1).

3.3 ANPG for response to ICls The optimal efficacy of all AGC patients was evaluated in the study, and the results were as follows: 111 (41.4\%) patients had progressive disease (PD), 4 (1.5\%) patients had CR, 78 (29.1\%) patients had PR, and 75 (28\%) patients had SD. The ORR was $30.6 \%$ and DCR was $58.6 \%$ (Table 2). Patients with poor, intermediate, and good ANPG did not show clear difference in DCR $(50.9 \%$ vs $55.9 \%$ vs $66.3 \%, \mathrm{p}=0.134)$, or in ORR $(27.3 \%$ vs $34.7 \%$ vs $27.4 \%$; $P=0.425)$ (Table 2 ).

3.4 ANPG for PFS of AGC patients Among 268 AGC patients, 220 (82.1\%) patients had tumor progression within the last follow-up date of July 1, 2021. Patients in good ANPG group were closely related to longer PFS, compared to those in the intermediate and poor ANPG group (5.6 months vs 5.3 months vs 3.4 months; $P=0.002$ ) (Figure 1a and Table 3). Univariate and multivariate analyses of factors associated with PFS were shown in Table 3. In univariate analysis, patients with a good PS (ECOG PS of 0-1), with no ascites, or with no pleural fluid showed improved OS. Patients did not reach PD before immunotherapy, and those who were treated with ICls combined with chemotherapy, who were treated with the 1st line $\mathrm{ICl}$, and who were treated with pembrolizumab were also associated with improved PFS. Multivariate analysis revealed that the poor ANPG and the intermediate ANPG were independently correlated with an over 1.9 times risk of disease progression $(\mathrm{HR}=1.901 ; 95 \% \mathrm{Cl}, 1.314-2.750 ; \mathrm{P}=0.001)$ and an over 1.3 times risk of disease progression $(\mathrm{HR}=1.385 ; 95 \% \mathrm{Cl}, 1.004-1.911 ; \mathrm{P}=0.048)$ than the good ANPG. Moreover, patients who were treated with ICls combined with chemotherapy, who were treated with the $1 \mathrm{st}$ line ICls, and who were treated with pembrolizumab were also independently associated with improved PFS. Patients treated with ICls after $1 \mathrm{st}$ line were independently correlated with an over 1.6 times risk of disease progression ( $\mathrm{HR}=1.699 ; 95 \% \mathrm{Cl}, 1.244-2.320 ; \mathrm{P}=0.001)$ than those treated with the 1 st line ICls. Patients treated with nivolumab were independently correlated with an over 1.9 times risk of disease 
progression $(\mathrm{HR}=1.972 ; 95 \% \mathrm{Cl}, 1.259-3.089 ; \mathrm{P}=0.003)$ than those treated with pembrolizumab. Patients treated with ICls combined without chemotherapy were independently correlated with an over 1.4 times risk of disease progression $(\mathrm{HR}=1.424 ; 95 \% \mathrm{Cl}, 1.034-1.961 ; \mathrm{P}=0.03)$ than those treated with ICls combined with chemotherapy.

3.5 ANPG for OS of AGC patients Among 268 AGC patients, 175 (65.3\%) patients died within the last follow-up date of July 1, 2021. Patients in the good ANPG group were closely related to longer OS, compared to those in the intermediate and poor ANPG group (17.8 months vs 11.8 months vs 8.2 months; $\mathrm{P}=0.003$ ) (Figure $1 \mathrm{~b}$ and Table 3). Univariate and multivariate analyses of factors associated with OS were shown in Table 3. In univariate analysis, In univariate analysis, patients with fewer organ metastases (<3), with a good PS (ECOG PS of 0-1), with no ascites, or with no pleural fluid showed improved OS. Patients did not reach PD before immunotherapy, and those who were treated with ICls combined with chemotherapy, who were treated with the $1 \mathrm{st}$ line ICls, and who were treated with pembrolizumab were also associated with improved OS. Multivariate analysis revealed that the poor ANPG and the intermediate ANPG were independently correlated with an over 2 times risk of death $(\mathrm{HR}=2.003 ; 95 \% \mathrm{Cl}, 1.306-3.072 ; \mathrm{P}=0.001)$ and an over 1.4 times risk of death $(\mathrm{HR}=1.484 ; 95 \% \mathrm{Cl}, 1.046-$ 2.106; $P=0.027$ ) than the good ANPG. Moreover, patients with no pleural fluid and with a good PS (ECOG PS of 0-1) were independently associated with improved OS. Patients who were treated with the 1 st line ICls and who were treated with pembrolizumab were also independently associated with improved OS. Patients with pleural fluid were independently correlated with an over 2.2 times risk of death $(H R=2.252$; $95 \% \mathrm{Cl}, 1.333-3.804 ; \mathrm{P}=0.002$ ) than those without pleural fluid. Patients with a good PS (ECOG PS of 0-1) were independently correlated with an over 1.9 times risk of death $(\mathrm{HR}=1.996 ; 95 \% \mathrm{Cl}, 1.122-3.552 ; \mathrm{P}$ $=0.019$ ) than those with a poor PS (ECOG PS of $\geq 2$ ). Patients treated with ICls after 1 st line were independently correlated with an over 1.8 times risk of death $(\mathrm{HR}=1.817 ; 95 \% \mathrm{Cl}, 1.315-2.512 ; \mathrm{P}<0.001)$ than those treated with the $1 \mathrm{st}$ line ICls. Patients treated with nivolumab were independently correlated with an over 1.5 times risk of death $(\mathrm{HR}=1.577 ; 95 \% \mathrm{Cl}, 1.005-2.476 ; \mathrm{P}=0.048)$ than those treated with pembrolizumab.

\subsection{Association of the ANPG with outcomes in lines of immunotherapy of 1 or a large number of lines of immunotherapy $(\geq 2)$ : Subgroup Analysis Multivariate analysis revealed that patients treated with the 1st} line ICls were independently correlated with improved OS and PFS. Our study then conducted subgroup analysis based on different lines of immunotherapy. Univariate analyses of association of the ANPG with outcomes in lines of immunotherapy of 1 was shown in Table 4. For the 143 patients with the 1 st line ICls, $23(41.8 \%)$ patients were in the poor ANPG group, 63(53.4\%) patients were in the intermediate ANPG group, and 39 (41.1\%) patients were in the good ANPG group. Pateints of the good ANPG group had improved PFS than the intermediate ANPG group , and the poor ANPG group (14.6 months vs 8.1 months vs 5.8 months, $P=0.021$ ) (Figure2a). The poor ANPG was correlated with an over 2.3 times risk of disease progression ( $\mathrm{HR}=2.328 ; 95 \% \mathrm{Cl}, 1.269-4.272 ; \mathrm{P}=0.006)$ than the good ANPG. However, patients with good, intermediate, and poor ANPG did not show clear difference in OS (29 months vs 15.8 months vs 12.9 months, $P=0.218$ ) (Figure 2b). Univariate analyses of association of the ANPG with outcomes in lines of a large number of lines of immunotherapy $(\geq 2)$ was shown in Table 5. For 125 patients with ICls in 
subsequent lines, 32(58.2\%) patients were in the poor ANPG group, 55(46.6\%) patients were in the intermediate ANPG group, and 56(58.9\%) patients were in the good group. Pateints of the good ANPG group had improved PFS and OS than the intermediate ANPG group, and the poor ANPG group (3.3 months vs 3.4 months vs 2.2 months, 11.9 months vs 9.1 months vs 3.7 months; $P=0.026, P=0.001$ ) (Figure 3a,3b). The poor ANPG was correlated with an over 1.7 times risk of disease progression (HR= $1.773 ; 95 \% \mathrm{Cl}, 1.126-2.791 ; \mathrm{P}=0.013)$ and an over 2.3 times risk of death $(\mathrm{HR}=2.371 ; 95 \% \mathrm{Cl}, 1.467-3.834$; $P=0.006)$ than the good ANPG. However, patients with intermediate, and good ANPG did not show clear difference in OS and PFS $(P=0.148, P=0.790)$.

\subsection{Association of the ANPG with outcomes in ICls combined with chemotherapy or combined without chemotherapy: Subgroup Analysis Multivariate analysis revealed that patients treated with the ICls} combined with chemotherapy were independently correlated with improved OS and PFS. Our study then conducted subgroup analysis based on different schemes of immunotherapy. Univariate analyses of association of the ANPG with outcomes in ICls combined with chemotherapy was shown in Table 6. For the 173 patients treated with the ICls combined with chemotherapy, 32(58.2\%) patients were in the poor ANPG group, 82(64.6\%) patients were in the intermediate ANPG group, and 59(62.1\%) patients were in the good ANPG group. Pateints of the good ANPG group had improved PFS than the intermediate ANPG group , and the poor ANPG group (6.7 months vs 6 months vs 3.7 months, $P=0.049$ )(Figure 4a). The poor ANPG was correlated with an over 1.6 times risk of disease progression ( $\mathrm{HR}=1.649 ; 95 \% \mathrm{Cl}, 1.027-2.648$; $\mathrm{P}=0.039)$ and an over 1.8 times risk of death $(\mathrm{HR}=1.827 ; 95 \% \mathrm{Cl}, 1.058-3.155 ; \mathrm{P}=0.031)$ than the good ANPG. However, patients with good, intermediate, and poor ANPG did not show clear difference in OS (20.9 months vs 14.9 months vs 8.7 months, $P=0.091$ ) (Figure $4 \mathrm{~b}$ ). Univariate analyses of association of the ANPG with outcomes in lines of immunotherapy of 1 shown in Table 7 . For 95 patients treated with the ICls combined without chemotherapy, 23 (41.8\%) patients were in the poor ANPG group, 36 (30.5\%) patients were in the intermediate ANPG group, and 36 (37.9\%) patients were in the good group. Pateints of the good ANPG group had improved PFS and OS than the intermediate ANPG group, and the poor ANPG group (3.2 months vs 2.8 months vs 2.2 months, 12.7 months vs 8.1 months vs 5.4 months; $\mathrm{P}=0.032, \mathrm{P}=0.007$ ) (Figure5a,5b). The poor ANPG was correlated with an over 2.4 times risk of disease progression $(\mathrm{HR}=2.422 ; 95 \% \mathrm{Cl}, 1.367-4.292 ; \mathrm{P}=0.002)$ and an over 2.1 times risk of death $(\mathrm{HR}=2.184$; $95 \% \mathrm{Cl}, 1.194-3.994 ; \mathrm{P}=0.011)$ than the good ANPG. However, patients with good and intermediate ANPG did not show clear difference in OS and PFS( $P=0.096, P=0.051)$.

\section{Discussion}

The status of immunotherapy in the field of GC treatment has an increasing trend worldwide annually ${ }^{[7,18]}$. Judging from the current clinical trial results, the effect of immune checkpoint inhibitors is very obvious ${ }^{[19]}$. Whereas, immunotherapy drugs are expensive and prone to drug resistance and even super-progress ${ }^{[20,21]}$. Therefore, looking for predictive indicators is an important problem to be solved urgently that can accurately identify the population with the advantage of immunotherapy to achieve precise immunotherapy as much as possible. However, the current evaluation of biomarkers for 
immunotherapy is relatively limited ${ }^{[15]}$. Peripheral blood inflammatory complex index such as LIPI, NLR, $\mathrm{PLR}, \mathrm{Hb}$ levels had demonstrated a convenient and promising prognostic biomarker for $\mathrm{GC}^{[12-16]}$. The highly heterogeneous characteristics of GC may limit the accuracy of a single biomarker for screening immunotherapy benefiting populations ${ }^{[22]}$. In contrast, the combination of multiple indicators can provide more targeted information for the detection of potential immune benefit subgroups. Sun $\mathrm{H}$ et al. found that patients with the good ANPG was independently associated with better prognosis for NSCLC patients $^{[17]}$. ANPG was a composite biomarker of neutrophil and albumin ${ }^{[17]}$. The high levels of albumin ( $\geq$ the cut-off value) and neutrophil ( $\geq$ the cut-off value) were considered to be two risk factors for ANPG. Based on these two risk factors, patients were categorized into 3 groups: the risk factor number for the "good" group was 0 , for the "intermediate" group was 1 , and for the "poor" group was $2^{[17]}$. However, there is no research on ANPG in immunotherapy of patients with tumor. Thus, we carried out the present study to explore the clinical value of ANPG in predicting prognostic outcomes of AGC patients following ICls treatment. In our study, the cut-off value of albumin was $38 \mathrm{~g} / \mathrm{L}$ obtained by the median value, and neutrophil was $4.16 \mathrm{~g} / \mathrm{L}$ estimated by the average value. We found that patients in good ANPG group were independently related to longer PFS and OS, compared to those in the intermediate and poor ANPG group. The prognostic value of ANPG in AGC patients treated with ICls was consistent with in NSCLC patients of the study of Sun $\mathrm{H}$ et al ${ }^{[17]}$. Moreover, subgroup analysis of our study, based on different lines of immunotherapy, found that ANPG was correlated with PFS but not OS of AGC patients treated with the 1 st line ICls and was correlated with PFS and OS of AGC patients treated with ICls in subsequent lines. Subgroup analysis of our study, different schemes of immunotherapy, found that ANPG was correlated with PFS but not OS of AGC patients treated with ICls combined with chemotherapy and was correlated with PFS and OS of AGC patients treated with ICls combined without chemotherapy. Baicun Hou et al. noticed that patients with a good PS (ECOG PS of 0-1) were also independently associated with PFS and OS for AGC patients treated with ICls ${ }^{[16]}$. But, in our study, patients had a good PS (ECOG PS of 0-1) were independently associated with improved OS, but without improved PFS. Baicun Hou et al. noticed that patients treated with combination of immunotherapy and other therapies were associated with improved OS and PFS ${ }^{[16]}$. Patients receiving ICls combined without chemotherapy were associated with shorter PFS but not OS in our study. We found patients treated with the 1 st line ICls were independently associated with improved PFS and OS. However, no clear difference of OS and PFS were observed between patients treated with the $1 \mathrm{st}$ line ICls and treated with ICls after the 1 st line in study of Baicun Hou et al. ${ }^{[16]}$. Baicun Hou et al. found that patients had fewer organ metastases $(<2)$ and treated with the 1 st line ICls were not independently associated with improved PFS and OS than those had more organ metastases $(\geq 2)^{[16]}$. We also found patients had fewer organ metastases $(<3)$ were not independently associated with improved PFS and OS. Baicun Hou et al. found that the type of ICls was not an independent factor affecting survival of AGC patients receiving immunotherapy ${ }^{[16]}$. However, our study found that patients treated with pembrolizumab were independently correlated with improved OS and PFS than those treated with nivolumab. In addition, our study firstly found that patients without pleural fluid were independently correlated with improved OS than those with pleural fluid, but without improved PFS. 
However, the mechanism of the correlation between these peripheral blood inflammatory complex index and the tumor prognosis is relatively complicated, and it still needs to be further explored through basic experiments and clinical trials. Some studies have found that this probably due to the tumor-immune microenvironment of patients ${ }^{[23,24]}$. In addition to direct immune killing effects on tumor cells, these biomarkers are also related to tumor immunostimulatory signals and the activation of effector cells. Neutrophils, one type of the most vital and abundant leukocytes in circulating blood, are the first-line defense to protect host from tissue damage and infections ${ }^{[25]}$. Neutrophils are derived from bone marrow hematopoietic stem cells and have chemotaxis, phagocytosis and bactericidal effect ${ }^{[26]}$. The reactive oxygen species released by neutrophils can damage DNA, which is related to the occurrence and development of tumors ${ }^{[27]}$. Increased number of neutrophils in peripheral blood can promote tumor metastasis and growth by releasing inflammatory mediators ${ }^{[28]}$. In addition, it can not only enhance the growth of tumor cells under the effect of tumor, its microenvironment reproduction and invasion can promote angiogenesis and mediate tumor immunosuppression ${ }^{[29]}$. Lymphocyte is an important component of cell for body's immune response function ${ }^{[30]}$. Elevated neutrophils can inhibit the immune attack ability of lymphocytes ${ }^{[31]}$. Albumin one type of the most vital biochemical Indicators, is related to nutritional status of patients with cancer ${ }^{[32]}$. Some studies found that hypoalbuminemia are associated with worse prognosis of patients with $\mathrm{GC}^{[33,34]}$. Some researchers thought if it was associated with other powerful clinical indicators, such as c-reactive protein (CRP), the albumin level as a prognostic indicator would be more convincing ${ }^{[35,36]}$. Nozoe $T$ et al. found glasgow prognostic score (GPS) which was a composite biomarker of albumin and CRP could be used as an positive prognostic indicator of patients with $\mathrm{GC}^{[36]}$. Zhang $\mathrm{J}$ et al. found that a composite biomarker of serum carcinoembryonic antigen (CEA) and fibrinogen/ albumin ratio also could be used as an positive prognostic indicator of patients with $\mathrm{GC}^{[37]}$. Therefore, the higher level of neutrophils and the lower level of tumor patients get, the worse their prognosis will be. ANPG was a composite biomarker of neutrophil and albumin ${ }^{[17]}$. In other words, patients with good ANPG will have a better prognosis.

This study had some limitations, including a relatively small sample size with a mixed population of GC of cardia, GC of body/fundus, and GC of pylorus, as well as a lack of comparison of the three ANPG groups among the three cancers.

\section{Conclusion}

This study demonstrated that a composite biomarker of ANPG is independently correlated with the survival of AGC patients implementing immunotherapy. However, the possibility of using the complex index as an effective and economic prognostic biomarker to selected patients, those who are best suited to receiving ICls, needs further investigation in a larger prospective study.

\section{Abbreviations}


Gastric cancer (GC); advanced GC (AGC);verall survival (OS); programmed death ligand-1 (PD-L 1); immune checkpoint inhibitors (ICls); microsatellite steady-state (MSI);lung immune prognostic index (LIPI); neutrophil-lymphocyte ratio (NLR); platelet-lymphocyte ratio (PLR); hemoglobin ( $\mathrm{Hb}$ ); progression free survival (PFS); albumin and neutrophil combined prognostic grade (ANPG); non-small cell lung cancer (NSCLC); eastern cooperative oncology group performance status scores (ECOG PS); disease control rate $\triangle D C R$ ); overall response rate (ORR) ; complete response (CR); partial response (PR) ; stable disease (SD) ; progressive disease (PD); c-reactive protein (CRP); glasgow prognostic score (GPS); carcinoembryonic antigen (CEA)

\section{Declarations}

\section{ACKNOWLEDGEMENTS}

The author gratefully acknowledge the advice and insights of Dr Guanghai Dai, whose work is supported (or supported in part) by Senior Department of Oncology, the Fifth Medical Center, Chinese PLA General Hospital; and ZhiKuan Wang whose work is supported (or supported in part) by The Hainan Medical Center, Chinese PLA General Hospital.

\section{DATA AVAILABILITY STATEMENT}

The raw data supporting the conclusions of this article will be made available by the authors, without undue reservation.

\section{ETHICS STATEMENT}

This study was approved by the Ethics Committee of Chinese PLA General Hospital and was conducted according to the principles of the Declaration of Helsinki.

\section{AUTHOR CONTRIBUTIONS}

YP were in charge of writing and analysis. GD and ZK provided the guide and idea. All authors contributed to the article and approved the submitted version.

\section{Conflict of Interest}

The authors declare that the research was conducted in the absence of any commercial or financial relationships that could be construed as a potential conflict of interest.

\section{FUNDING}

Not applicable.

\section{References}


1. Siegel RL, Miller KD, Jemal A. Cancer statistics, 2020. CA Cancer J Clin. 2020 Jan;70(1):7-30. doi: 10.3322/caac. 21590 .

2. Chen LT, Satoh T, Ryu MH, Chao Y, Kato K, Chung HC, Chen JS, Muro K, Kang WK, Yeh KH, Yoshikawa T, Oh SC, Bai LY, Tamura T, Lee KW, Hamamoto Y, Kim JG, Chin K, Oh DY, Minashi K, Cho JY, Tsuda M, Sameshima H, Kang YK, Boku N. A phase 3 study of nivolumab in previously treated advanced gastric or gastroesophageal junction cancer (ATTRACTION-2): 2-year update data. Gastric Cancer. 2020 May;23(3):510-519. doi: 10.1007/s10120-019-01034-7.

3. Kato K, Satoh T, Muro K, Yoshikawa T, Tamura T, Hamamoto Y, Chin K, Minashi K, Tsuda M, Yamaguchi K, Machida N, Esaki T, Goto M, Komatsu Y, Nakajima TE, Sugimoto N, Yoshida K, Oki E, Nishina T, Tsuji A, Fujii H, Kunieda K, Saitoh S, Omuro Y, Azuma M, Iwamoto Y, Taku K, Fushida S, Chen LT, Kang YK, Boku N. A subanalysis of Japanese patients in a randomized, double-blind, placebo-controlled, phase 3 trial of nivolumab for patients with advanced gastric or gastroesophageal junction cancer refractory to, or intolerant of, at least two previous chemotherapy regimens (ONO-4538-12, ATTRACTION-2). Gastric Cancer. 2019 Mar;22(2):344-354. doi: 10.1007/s10120-018-0899-6.

4. Shitara K, Özgüroğlu M, Bang YJ, Di Bartolomeo M, Mandalà M, Ryu MH, Fornaro L, Olesiński T, Caglevic C, Chung HC, Muro K, Goekkurt E, Mansoor W, McDermott RS, Shacham-Shmueli E, Chen X, Mayo C, Kang SP, Ohtsu A, Fuchs CS; KEYNOTE-061 investigators. Pembrolizumab versus paclitaxel for previously treated, advanced gastric or gastro-oesophageal junction cancer (KEYNOTE-061): a randomised, open-label, controlled, phase 3 trial. Lancet. 2018 Jul 14;392(10142):123-133. doi: 10.1016/S0140-6736(18)31257-1.

5. Liang F. The KEYNOTE-061 trial. Lancet. 2019 Mar 16;393(10176):1098. doi: 10.1016/S01406736(18)33073-3.

6. Smyth EC, Petty RD. Pembrolizumab versus paclitaxel in gastro-oesophageal adenocarcinoma. Lancet. 2018 Jul 14;392(10142):97-98. doi: 10.1016/S0140-6736(18)31277-7.

7. anjigian YY, Shitara K, Moehler M, Garrido M, Salman P, Shen L, Wyrwicz L, Yamaguchi K, Skoczylas T, Campos Bragagnoli A, Liu T, Schenker M, Yanez P, Tehfe M, Kowalyszyn R, Karamouzis MV, Bruges R, Zander T, Pazo-Cid R, Hitre E, Feeney K, Cleary JM, Poulart V, Cullen D, Lei M, Xiao H, Kondo K, Li M, Ajani JA. First-line nivolumab plus chemotherapy versus chemotherapy alone for advanced gastric, gastro-oesophageal junction, and oesophageal adenocarcinoma (CheckMate 649): a randomised, open-label, phase 3 trial. Lancet. 2021 Jul 3;398(10294):27-40. doi: 10.1016/S0140-6736(21)007972.

8. Moehler M, Dvorkin M, Boku N, Özgüroğlu M, Ryu MH, Muntean AS, Lonardi S, Nechaeva M, Bragagnoli AC, Coşkun HS, Cubillo Gracian A, Takano T, Wong R, Safran H, Vaccaro GM, Wainberg ZA, Silver MR, Xiong H, Hong J, Taieb J, Bang YJ. Phase III Trial of Avelumab Maintenance After FirstLine Induction Chemotherapy Versus Continuation of Chemotherapy in Patients With Gastric Cancers: Results From JAVELIN Gastric 100. J Clin Oncol. 2021 Mar 20;39(9):966-977. doi: $10.1200 / J C 0.20 .00892$. 
9. Chung HC, Bang YJ, S Fuchs C, Qin SK, Satoh T, Shitara K, Tabernero J, Van Cutsem E, Alsina M, Cao ZA, Lu J, Bhagia P, Shih CS, Janjigian YY. First-line pembrolizumab/placebo plus trastuzumab and chemotherapy in HER2-positive advanced gastric cancer: KEYNOTE-811. Future Oncol. 2021 Feb;17(5):491-501. doi: 10.2217/fon-2020-0737.

10. Kelly RJ. Immunotherapy for esophageal and GC [J]. Am Soc Clin Oncol Educ Book, 2017, 37: 292300.

11. Kono K, Nakajima S, Mimura K. Current status of immune checkpoint inhibitors for GC[J]. GC, 2020, 23(4): 565-578.

12. Wei Q, Yuan X, Xu Q, Li J, Chen L, Ying J. Correlation Between Hemoglobin Levels and the Prognosis of First-Line Chemotherapy in Patients With Advanced GC. Cancer Manag Res (2020) 12:700919.doi: 10.2147/CMAR.S256074

13. Kim EY, Lee JW, Yoo HM, Park CH, Song KY. The Platelet-to-Lymphocyte Ratio Versus Neutrophil-toLymphocyte Ratio: Which is Better as a Prognostic Factor in GC. Ann Surg Oncol (2015) 22(13):4363-70.doi: 10.1245/ s10434-015-4518-z.

14. Matsuoka T, Yashiro M. Biomarkers of GC: Current Topics and Future Perspective. World J Gastroenterol (2018) 24(26):2818-32. doi: 10.3748/ wjg.v24.i26.2818.

15. Gou M, Zhang Y, Liu T, Qu T, Si H, Wang Z, Yan H, Qian N, Dai G. The Prognostic Value of Pretreatment Hemoglobin $(\mathrm{Hb})$ in Patients With Advanced or Metastatic GC Treated With Immunotherapy. Front Oncol. 2021 Jun 15;11:655716.doi:10.3389/fonc.2021.655716.

16. Hou B, Wang P, Liu T, Chen S, Li T, Zhang S, Tao H, Li X, Hu Y. Association of the pretreatment lung immune prognostic index with survival outcomes in advanced gastric cancer patients treated with immune checkpoint inhibitors. Clin Res Hepatol Gastroenterol. 2021 Jun 25;45(5):101748. doi: 10.1016/j.clinre.2021.101748.

17. Sun H, Hu P, Shen H, Dong W, Zhang T, Liu Q, Du J. Albumin and Neutrophil Combined Prognostic Grade as a New Prognostic Factor in Non-Small Cell Lung Cancer: Results from a Large Consecutive Cohort. PLoS One. 2015 Dec 14;10(12):e0144663. doi: 10.1371/journal.pone.0144663.

18. Tang ZQ, et al. Phase II study of neoadjuvant camrelizumab combined with chemoradiation for locally advanced proximal GC (Neo-PLANET, NCT03631615). Annals of Oncology (2021) 32 (suppl_5): S1040-S1075. 10.1016/annonc/annonc708.

19. Tan S, Li D, Zhu X. Cancer immunotherapy: Pros, cons and beyond. Biomed Pharmacother. 2020 Apr;124:109821. doi: 10.1016/j.biopha.2020.109821. Epub 2020 Jan 18.

20. Chen S, Gou M, Yan H, Fan M, Pan Y, Fan R, Qian N, Dai G. Hyperprogressive Disease Caused by PD-1 Inhibitors for the Treatment of Pan-Cancer. Dis Markers. 2021 Jun 22;2021:6639366. doi: $10.1155 / 2021 / 6639366$.

21. Kim RD, Chung V, Alese OB, El-Rayes BF, Li D, Al-Toubah TE, Schell MJ, Zhou JM, Mahipal A, Kim BH, Kim DW.A Phase 2 Multi-institutional Study of Nivolumab for Patients With Advanced Refractory Biliary Tract Cancer. JAMA Oncol. 2020 Jun 1;6(6):888-894. 
22. Huang X, Zhang J, Zheng Y. ANTXR1 Is a Prognostic Biomarker and Correlates With Stromal and Immune Cell Infiltration in Gastric Cancer. Front Mol Biosci. 2020 Dec 15;7:598221. doi: 10.3389/fmolb.2020.598221.

23. Balkwill F, Mantovani A. Inflammation and cancer: back to Virchow? Lancet. 2001 Feb 17;357(9255):539-45. doi: 10.1016/S0140-6736(00)04046-0.

24. Coussens L M, Werb Z. Inflammation and cancer. Nature. 2002;420:860-867.

25. Németh T, Sperandio M, Mócsai A. Neutrophils as emerging therapeutic targets. Nat Rev Drug Discov. 2020 Apr;19(4):253-275. doi: 10.1038/s41573-019-0054-z.

26. Garwicz D, Lennartsson A, Jacobsen SE, Gullberg U, Lindmark A. Biosynthetic profiles of neutrophil serine proteases in a human bone marrow-derived cellular myeloid differentiation model. Haematologica. 2005 Jan;90(1):38-44.

27. Wright HL, Lyon M, Chapman EA, Moots RJ, Edwards SW. Rheumatoid Arthritis Synovial Fluid Neutrophils Drive Inflammation Through Production of Chemokines, Reactive Oxygen Species, and Neutrophil Extracellular Traps. Front Immunol. 2021 Jan 5;11:584116. doi: 10.3389/fimmu.2020.584116.

28. Kumar S, Dikshit M. Metabolic Insight of Neutrophils in Health and Disease. Front Immunol. 2019 Sep 20;10:2099. doi: 10.3389/fimmu.2019.02099.

29. Li TJ, Jiang YM, Hu YF, Huang L, Yu J, Zhao LY, Deng HJ, Mou TY, Liu H, Yang Y, Zhang Q, Li GX. Interleukin-17-Producing Neutrophils Link Inflammatory Stimuli to Disease Progression by Promoting Angiogenesis in Gastric Cancer. Clin Cancer Res. 2017 Mar 15;23(6):1575-1585. doi: 10.1158/10780432.CCR-16-0617.

30. Manson J, Hoffman R, Chen S, Ramadan MH, Billiar TR. Innate-Like Lymphocytes Are Immediate Participants in the Hyper-Acute Immune Response to Trauma and Hemorrhagic Shock. Front Immunol. 2019 Jul 11;10:1501. doi: 10.3389/fimmu.2019.01501.

31. Justiz Vaillant AA, Qurie A. Immunodeficiency. 2021 Jun 30. In: StatPearls [Internet]. Treasure Island (FL): StatPearls Publishing; 2021 Jan-.

32. Laky B, Janda M, Bauer J, Vavra C, Cleghorn G, Obermair A. Malnutrition among gynaecological cancer patients. Eur J Clin Nutr. 2007 May;61(5):642-6. doi: 10.1038/sj.ejcn.1602540. Epub 2006 Oct 4.

33. Isik A, Okan I, Firat D, Yilmaz B, Akcakaya A, Sahin M. A new prognostic strategy for gastric carcinoma: albumin level and metastatic lymph node ratio. Minerva Chir. 2014 Jun;69(3):147-53.

34. Wu M, Pan Y, Jia Z, Wang Y, Yang N, Mu J, Zhou T, Guo Y, Jiang J, Cao X. Preoperative Plasma Fibrinogen and Serum Albumin Score Is an Independent Prognostic Factor for Resectable Stage II-III Gastric Cancer. Dis Markers. 2019 Oct 29;2019:9060845. doi: 10.1155/2019/9060845.

35. Tomita M, Ayabe T, Chosa E, Nakamura K. Prognostic significance of pre- and postoperative glasgow prognostic score for patients with non-small cell lung cancer. Anticancer research. 2014; 34(6):313740. Epub 2014/06/13. 
36. Nozoe T, Iguchi T, Egashira A, Adachi E, Matsukuma A, Ezaki T. Significance of modified Glasgow prognostic score as a useful indicator for prognosis of patients with gastric carcinoma. Am J Surg. 2011 Feb;201(2):186-91. doi: 10.1016/j.amjsurg.2010.01.030.

37. Zhang J, Ruan J, Wang W, Lu Y, Wang H, Yu X, Wang H, Teng L. Prognostic Value of the Combination of CEA and Fibrinogen/Albumin Ratio in Resectable Gastric Cancer. Cancer Manag Res. 2020 Apr 23;12:2767-2775. doi: 10.2147/CMAR.S246566.

\section{Tables}

Table 1 General data and clinical feature 


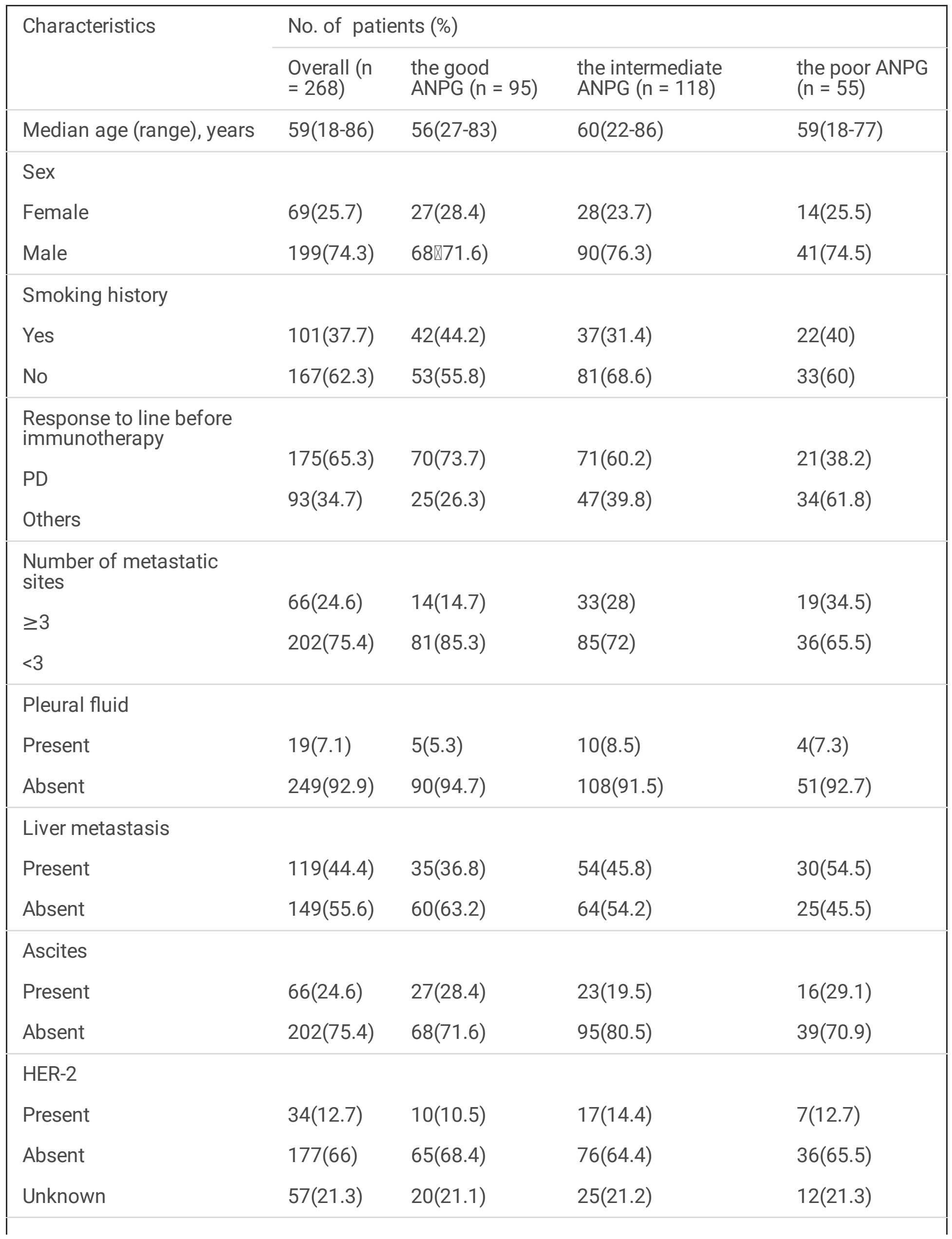




\begin{tabular}{|c|c|c|c|c|}
\hline \multicolumn{5}{|c|}{ Lines of immunotherapy } \\
\hline$\geq 2$ & $143(53.4)$ & $56(58.9)$ & $55(46.6)$ & $32(58.2)$ \\
\hline$<2$ & $125(46.6)$ & $39(41.1)$ & $63(53.4)$ & $23(41.8)$ \\
\hline \multicolumn{5}{|l|}{ Tumor_location } \\
\hline Cardia & $73(27.2)$ & $27(28.4)$ & 28(23.7) & $18(27.2)$ \\
\hline Body/Fundus & $110(41)$ & $39(41.1)$ & $47(39.8)$ & $24(41)$ \\
\hline Pylorus & $83(31)$ & 28(29.5) & $42(35.6)$ & 13(31) \\
\hline Unknown & $2(0.7)$ & $1(1.1)$ & $2(0.8)$ & $0(0)$ \\
\hline \multicolumn{5}{|l|}{ Smoking exposure } \\
\hline > 30 packs per year & 48(17.9) & 17(17.9) & 19(16.1) & $12(21.8)$ \\
\hline$\leq 30$ packs per year & $220(82.1)$ & $78(82.1)$ & $99(83.9)$ & $43(78.2)$ \\
\hline \multicolumn{5}{|c|}{ ECOG performance status } \\
\hline$\geq 2$ & $16(6)$ & $1(1.1)$ & $6(5.1)$ & $9(16.4)$ \\
\hline $0-1$ & 252(94) & $94(98.9)$ & $112(94.9)$ & $46(83.6)$ \\
\hline \multicolumn{5}{|l|}{ PD-1 inhibition agent } \\
\hline Pembrolizumab & $36(13.4)$ & 14(14.7) & 16(13.6) & $6(10.9)$ \\
\hline Nivolumab & $88(32.8)$ & $29(30.5)$ & $35(29.7)$ & $24(43.6)$ \\
\hline Other & 144(53.7) & $52(54.7)$ & $67(56.8)$ & $25(45.5)$ \\
\hline \multicolumn{5}{|l|}{$\begin{array}{l}\text { ICls combined with } \\
\text { chemotherapy }\end{array}$} \\
\hline No & $95(35.4)$ & $36(37.9)$ & $36(30.5)$ & $23(41.8)$ \\
\hline
\end{tabular}

Table 2 Relationship between ANPG groups and response to anti-PD-1 treatment 


\begin{tabular}{|c|c|c|c|c|c|}
\hline \multirow{3}{*}{$\begin{array}{l}\text { Best Overall } \\
\text { Respons }\end{array}$} & \multicolumn{3}{|c|}{ No. of Patients (\%) } & & \multirow{3}{*}{$\begin{array}{l}\mathrm{P} \\
\text { value }\end{array}$} \\
\hline & \multirow{2}{*}{$\begin{array}{l}\text { Overall } \\
\mathrm{n}=110\end{array}$} & $\begin{array}{l}\text { the good } \\
\text { ANPG }\end{array}$ & $\begin{array}{l}\text { the intermediate } \\
\text { ANPG }\end{array}$ & $\begin{array}{l}\text { the poor } \\
\text { ANPG }\end{array}$ & \\
\hline & & $\mathrm{n}=38$ & $\mathrm{n}=72$ & $\mathrm{n}=72$ & \\
\hline $\mathrm{CR}$ & $4 \rrbracket 1.5 \rrbracket$ & $1 \otimes 1.1 \otimes$ & $2 \otimes 1.7 \rrbracket$ & $1 \otimes 1.8 \otimes$ & 0.579 \\
\hline PR & $78 \rrbracket 29.1 \rrbracket$ & $25(26.3)$ & $39 \bowtie 33.1)$ & $14(25.5)$ & 0.448 \\
\hline SD & $75 \rrbracket 28 \rrbracket$ & $37(38.9)$ & $25(21.2)$ & $13(23.6)$ & 0.012 \\
\hline PD & $\begin{array}{l}111 \\
\square 41.4 \rrbracket\end{array}$ & $32(33.7)$ & $52(44.1)$ & $27(49.1)$ & 0.134 \\
\hline Objective response & $82(30.6)$ & $26(27.4)$ & $41 \rrbracket 34.7 \rrbracket$ & $15 \llbracket 27.3 \rrbracket$ & 0.425 \\
\hline $\begin{array}{l}\text { Disease control } \\
\text { rate }\end{array}$ & $\begin{array}{l}157 \\
\otimes 58.6 \rrbracket\end{array}$ & $63(66.3)$ & $66 \rrbracket 55.9 \rrbracket$ & $28 \otimes 50.9 \rrbracket$ & 0.134 \\
\hline
\end{tabular}

Table 3 Univariate and multivariate analyses of factors associated with overall survival and progressionfree survival 


\section{OS}

ECOG performance

status, No.

0-1

$\geq 2$

13.1

1 [Reference]

1 [Reference]

2

4.466(2.647- $<0.001 *$

7.534)

1.996(1.122-

3.552)

0.019

Lines of

immunotherapy

$<2$

20.9

1 [Reference]

1 [Reference]

$\geq 2$

9.1

2.106(1.543- $<0.001^{*}$

2.874)

$1.817 \otimes 1.315-<0.001^{*}$

2.512)

Ascites

Absent

13.1

1 [Reference]

1 [Reference]

Present

11.1

1.443(1.039- $\quad 0.029 *$

2.003)

$1.174 \rrbracket 0.821-$

$1.677 \rrbracket$

0.380

Pleural fluid

Absent

12.8

1 [Reference]

1 [Reference]

Present

6.0

$2.249\left(1.340-\quad 0.002^{*}\right.$

3.776)

2.252(1.333- 0.002 3.804】

Number of metastatic

sites

$<3$

14

9

1 [Reference]

1 [Reference]

$\geq 3$

1.556(1.122- $0.008 *$

$1.275(0.901-$

1.806)

0.170

2.157)

Response to line before immunotherapy

Others

18.3

1 [Reference]

1 [Reference]

PD

11.1

1.543(1.112-

0.001 *

1.065(0.724-

1.565)

0.750

2.143)

ICls combined with

chemotherapy

Yes

15

1 [Reference]

1 [Reference]

No

9.3

1.518(1.121- $\quad 0.007$

2.055)

1.151(0.810-

1.635)

0.434

PD-1 inhibition agent

Pembrolizumab

12.7

1 [Reference]

1 [Reference]

Nivolumab

5.7

19.7

$1.659(1.062-$

$0.026 *$

$1.577 \rrbracket 1.005$

2.476》

0.048

0.027 *

0.059 

0.603(0.385-
0.945 )
$0.639 \rrbracket 0.402-$
$1.017 \rrbracket$

ANPG

\begin{tabular}{|c|c|c|c|c|c|}
\hline The good & 17.8 & 1 [Reference] & & 1 [Reference] & \\
\hline The intermediate & 11.8 & $\begin{array}{l}1.333 \otimes 0.943- \\
1885 \rrbracket\end{array}$ & 0.103 & $\begin{array}{l}1.484 \rrbracket 1.046- \\
106 \rrbracket\end{array}$ & 0.027 \\
\hline \multirow[t]{2}{*}{ The poor } & \multirow[t]{2}{*}{8.2} & & \multirow[t]{2}{*}{0.001} & & \multirow[t]{2}{*}{0.001} \\
\hline & & $\begin{array}{l}1.993 \rrbracket 1.330- \\
2.986 \rrbracket\end{array}$ & & $\begin{array}{l}2.003 \bigotimes 1.306- \\
3.072 \rrbracket\end{array}$ & \\
\hline Patient Characteristics & survival(months $\rrbracket$ & $\begin{array}{l}\text { Univariate } \\
\text { Analysis HR } \\
\text { \$95\%Cl }\end{array}$ & $P$ & $\begin{array}{l}\text { Multivariate } \\
\text { Analysis HR } \\
\text { ख95\%Cl区 }\end{array}$ & $\mathrm{P}$ \\
\hline
\end{tabular}

\section{PFS}

ECOG performance

status, No.

0-1

5.3

1 [Reference]

1 [Reference]

$\geq 2$

1.9

2.526(1.511-

4.222)

$<0.001^{*}$

1.063(0.601-

1.878)

0.835

Lines of

immunotherapy

$<2$

8.1

1 [Reference]

1 [Reference]

$\geq 2$

$2.083(1.586-$ 2.737)

$<0.001^{*}$

1.699(1.244-

2.320)

0.001

Ascites

\begin{tabular}{llllll} 
Absent & 5.2 & 1 [Reference] & \multicolumn{3}{c}{1 [Reference] } \\
Present & 3.6 & $1.491(1.103-$ & $0.009 *$ & $1.381 \llbracket 0.989-$ & 0.058 \\
& & $2.015)$ & & $1.928 \rrbracket$ &
\end{tabular}

Pleural fluid

\begin{tabular}{llllll} 
Absent & 5.3 & 1 [Reference] & \multicolumn{3}{c}{1 [Reference] } \\
Present & 2.5 & $2.029(1.242-$ & $0.005^{\star}$ & $1.6050 .936-$ & 0.085 \\
& & $3.317)$ & & $2.751 \rrbracket$ &
\end{tabular}

Response to line before immunotherapy

Others

5.8

1 [Reference]

1 [Reference]

PD

4.2

$1.330(1.000-$

1.770)

$0.048^{*}$

0.883(0.628-

1.241)

ICls combined with

chemotherapy

Yes

5.8

1 [Reference]

1 [Reference]

No

1.588(1.212-

2.081)

Page 19/24 
PD-1 inhibition agent

\begin{tabular}{|c|c|c|c|c|c|}
\hline Pembrolizumab & 6.9 & 1 [Reference] & & 1 [Reference] & \\
\hline Nivolumab & 2.4 & $1.835(1.193-$ & $0.006^{*}$ & $\begin{array}{l}1.972 \bigotimes 1.259- \\
3\end{array}$ & 0.003 \\
\hline Others & 5.8 & $\begin{array}{l}0.980(0.646- \\
1.485)\end{array}$ & 0.992 & $\begin{array}{l}1.073 \otimes 0.700- \\
1.646 \rrbracket\end{array}$ & 0.747 \\
\hline ANPG & & & & & \\
\hline The good & 5.6 & 1 [Reference] & 0.003 & 1 [Reference] & \\
\hline The intermediate & 5.3 & $\begin{array}{l}1.128 \rrbracket 0.829- \\
1.534 \rrbracket\end{array}$ & 0.444 & $\begin{array}{l}1.385 \otimes 1.004- \\
1.911 \rrbracket\end{array}$ & 0.048 \\
\hline The poor & 3.4 & $\begin{array}{l}1.857 \rrbracket 1.295- \\
2.662 \rrbracket\end{array}$ & 0.001 & $\begin{array}{l}1.901 \otimes 1.314- \\
2.750 \rrbracket\end{array}$ & 0.001 \\
\hline
\end{tabular}

Table 4 Univariate analyses of ANGP associated with overall survival and progression-free survival of AGC patients treated with $1^{\text {st }}$ line ICls

\begin{tabular}{|c|c|c|c|c|c|c|}
\hline \multirow{3}{*}{$\begin{array}{l}\text { ANGP } \\
\text { classification }\end{array}$} & \multicolumn{6}{|c|}{ Patients treated with the 1 st line ICls } \\
\hline & \multicolumn{3}{|c|}{ OS (months) } & \multicolumn{3}{|c|}{ PFS (months) } \\
\hline & Median & $\mathrm{HR}(95 \% \mathrm{Cl})$ & $\begin{array}{l}\mathrm{P} \\
\text { value }\end{array}$ & Median & $\mathrm{HR}(95 \% \mathrm{Cl})$ & $\begin{array}{l}\mathrm{p} \\
\text { value }\end{array}$ \\
\hline The good & 29 & 1 [Reference] & & 14.6 & 1 [Reference] & \\
\hline The Intermediate & 15.8 & $\begin{array}{l}1.639 \text { (0.906- } \\
2.967)\end{array}$ & 0.103 & 8.1 & $\begin{array}{l}1.484(0.892- \\
2.469)\end{array}$ & 0.129 \\
\hline The poor & 12.9 & $\begin{array}{l}1.682(0.793- \\
3.566)\end{array}$ & 0.175 & 5.8 & $\begin{array}{l}2.328(1.269- \\
4.272)\end{array}$ & 0.006 \\
\hline$P$ value & 0.218 & & & 0.021 & & \\
\hline
\end{tabular}

Table 5 Univariate analyses of ANGP associated with overall survival and progression-free survival of AGC patients treated with ICls in subsequent lines 


\begin{tabular}{|c|c|c|c|c|c|c|}
\hline \multirow{3}{*}{$\begin{array}{l}\text { ANGP } \\
\text { classification }\end{array}$} & \multicolumn{6}{|c|}{ Patients treated with ICls in subsequent lines } \\
\hline & \multicolumn{3}{|c|}{ OS (months) } & \multicolumn{3}{|c|}{ PFS (months) } \\
\hline & Median & $\mathrm{HR}(95 \% \mathrm{Cl})$ & $\begin{array}{l}\mathrm{P} \\
\text { value }\end{array}$ & Median & $\mathrm{HR}(95 \% \mathrm{Cl})$ & $\begin{array}{l}\mathrm{p} \\
\text { value }\end{array}$ \\
\hline The good & 11.9 & 1 [Reference] & & 3.3 & 1 [Reference] & \\
\hline The Intermediate & 9.1 & $\begin{array}{l}1.379(0.892- \\
2.133)\end{array}$ & 0.148 & 3.4 & $\begin{array}{l}1.056(0.708- \\
1.575)\end{array}$ & 0.790 \\
\hline The poor & 3.7 & $\begin{array}{l}2.371(1.467- \\
3.834)\end{array}$ & $<0.001$ & 2.2 & $\begin{array}{l}1.773(1.126- \\
2.791)\end{array}$ & 0.013 \\
\hline$P$ value & 0.001 & & & 0.026 & & \\
\hline
\end{tabular}

Table 6 Univariate analyses of ANGP associated with overall survival and progression-free survival of AGC patients treated with ICls combined with chemotherapy.

\begin{tabular}{|c|c|c|c|c|c|c|}
\hline \multirow{3}{*}{$\begin{array}{l}\text { ANGP } \\
\text { classification }\end{array}$} & \multicolumn{6}{|c|}{ Patients treated with ICls combined with chemotherapy } \\
\hline & \multicolumn{3}{|c|}{ OS (months) } & \multicolumn{3}{|c|}{ PFS (months) } \\
\hline & Median & $\mathrm{HR}(95 \% \mathrm{Cl})$ & $\begin{array}{l}P \\
\text { value }\end{array}$ & Median & $\mathrm{HR}(95 \% \mathrm{Cl})$ & $\begin{array}{l}\mathrm{p} \\
\text { value }\end{array}$ \\
\hline The good & 20.9 & 1 [Reference] & & 6.7 & 1 [Reference] & \\
\hline The Intermediate & 14.9 & $\begin{array}{l}1.255(0.801- \\
1.965)\end{array}$ & 0.321 & 6 & $\begin{array}{l}0.955(0.664- \\
1.471)\end{array}$ & 0.955 \\
\hline The poor & 8.7 & $\begin{array}{l}1.827(1.058- \\
3.155)\end{array}$ & 0.031 & 3.7 & $\begin{array}{l}1.649(1.027- \\
2.648)\end{array}$ & 0.039 \\
\hline$P$ value & 0.091 & & & 0.049 & & \\
\hline
\end{tabular}

Table 7 Univariate analyses of ANGP associated with overall survival and progression-free survival of AGC patients treated with ICls combined without chemotherapy. 


\begin{tabular}{|c|c|c|c|c|c|c|}
\hline \multirow{3}{*}{$\begin{array}{l}\text { ANGP } \\
\text { classification }\end{array}$} & \multicolumn{6}{|c|}{ Patients treated with ICls combined without chemotherapy } \\
\hline & \multicolumn{3}{|c|}{ OS (months) } & \multicolumn{3}{|c|}{ PFS (months) } \\
\hline & Median & $\mathrm{HR}(95 \% \mathrm{Cl})$ & $\begin{array}{l}P \\
\text { value }\end{array}$ & Median & $\mathrm{HR}(95 \% \mathrm{Cl})$ & $\begin{array}{l}\mathrm{p} \\
\text { value }\end{array}$ \\
\hline The good & 12.7 & 1 [Reference] & & 3.2 & 1 [Reference] & \\
\hline The Intermediate & 8.1 & $\begin{array}{l}1.589(0.922- \\
2.741)\end{array}$ & 0.096 & 2.8 & $\begin{array}{l}1.650(0.998- \\
2.729)\end{array}$ & 0.051 \\
\hline The poor & 5.4 & $\begin{array}{l}2.184(1.194- \\
3.994)\end{array}$ & 0.011 & 2.2 & $\begin{array}{l}2.422(1.367- \\
4.292)\end{array}$ & 0.002 \\
\hline$P$ value & 0.032 & & & 0.007 & & \\
\hline
\end{tabular}

\section{Figures}

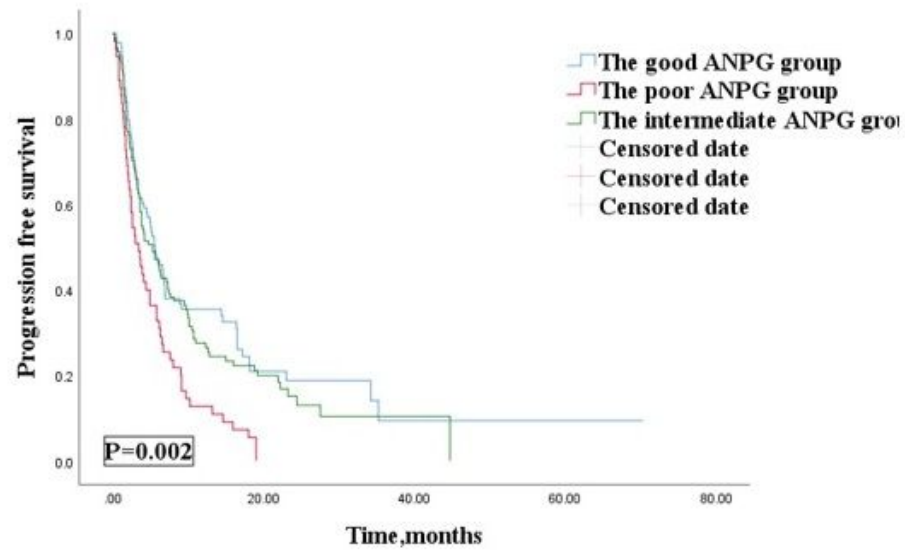

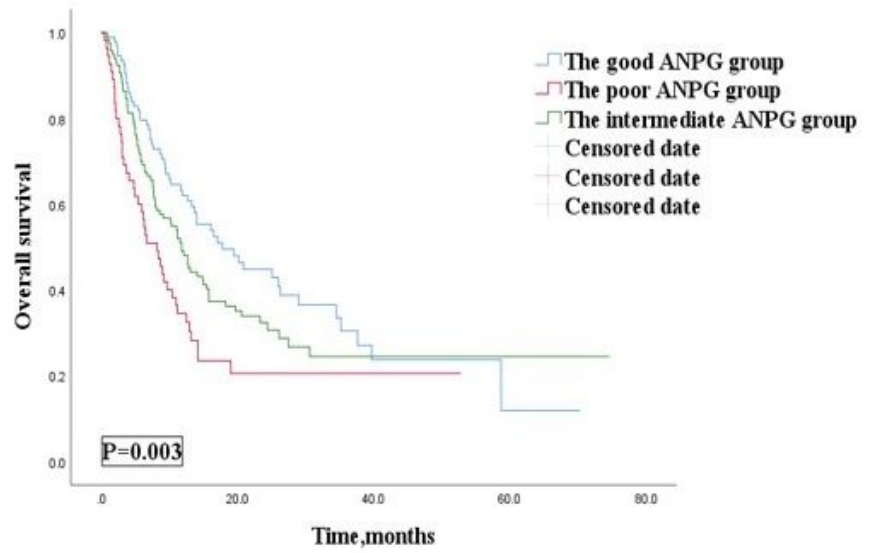

Figure 1

progression-free survival (PFS) (a) and Overall survival (OS) (b) according to the good ANPG, the intermediate ANPG and the poor ANPG groups of patients with AGC patients. 

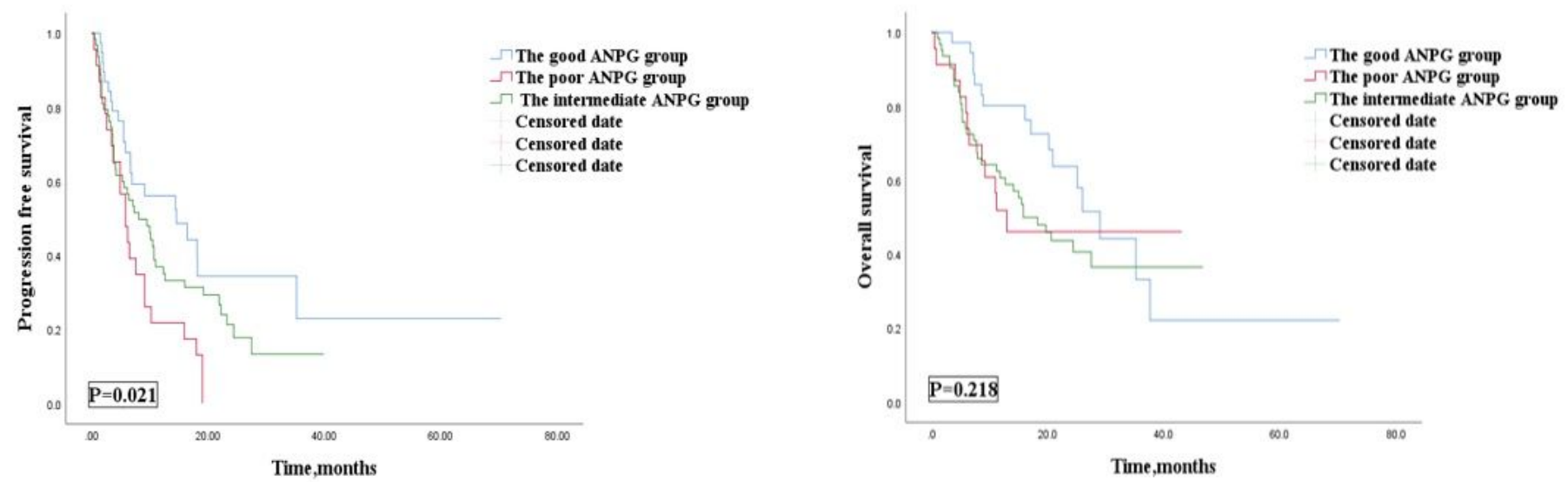

Figure 2

PFS (a)and (b) OS of the 1st line of patients with AGC, receiving PD-1 inhibitor cohort.

a

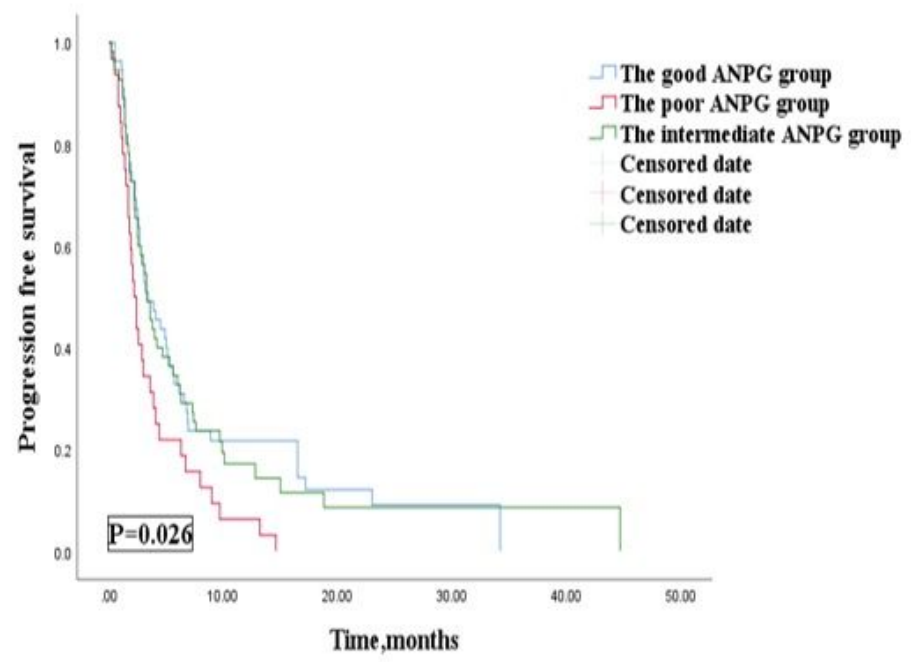

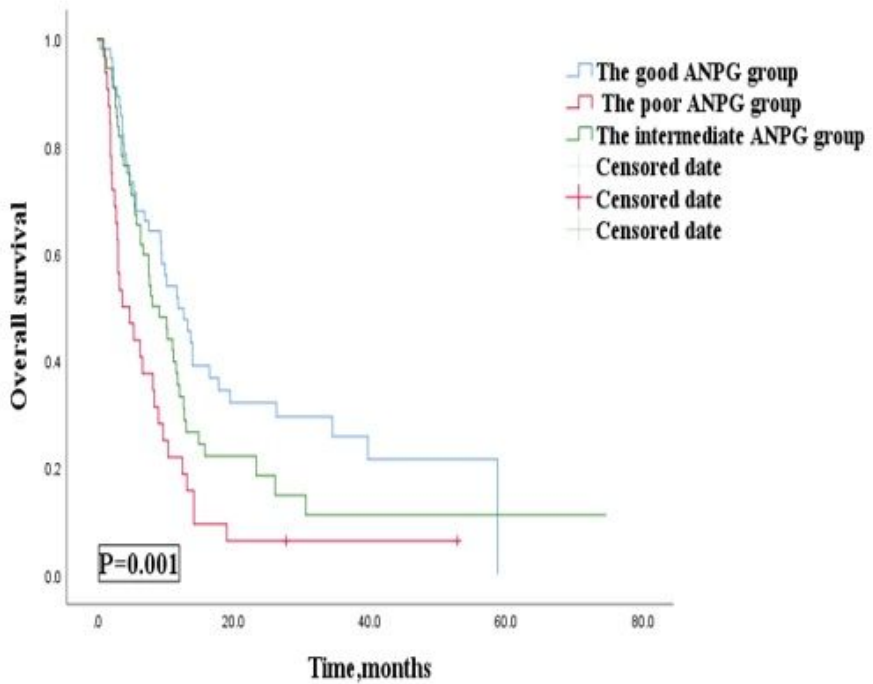

Figure 3

PFS (a)and (b) OS of the the multi-line of patients with AGC, receiving PD-1 inhibitor cohort. 

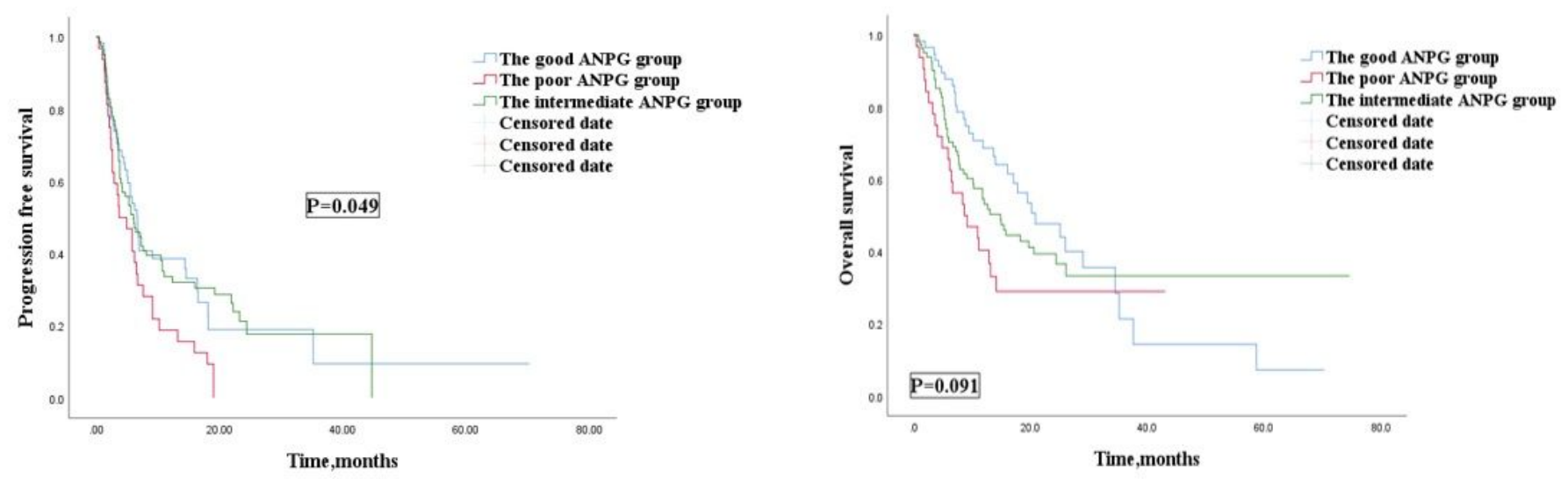

Figure 4

PFS (a)and (b) OS of AGC patients treated with ICls combined with chemotherapy, receiving PD-1 inhibitor cohort.

a

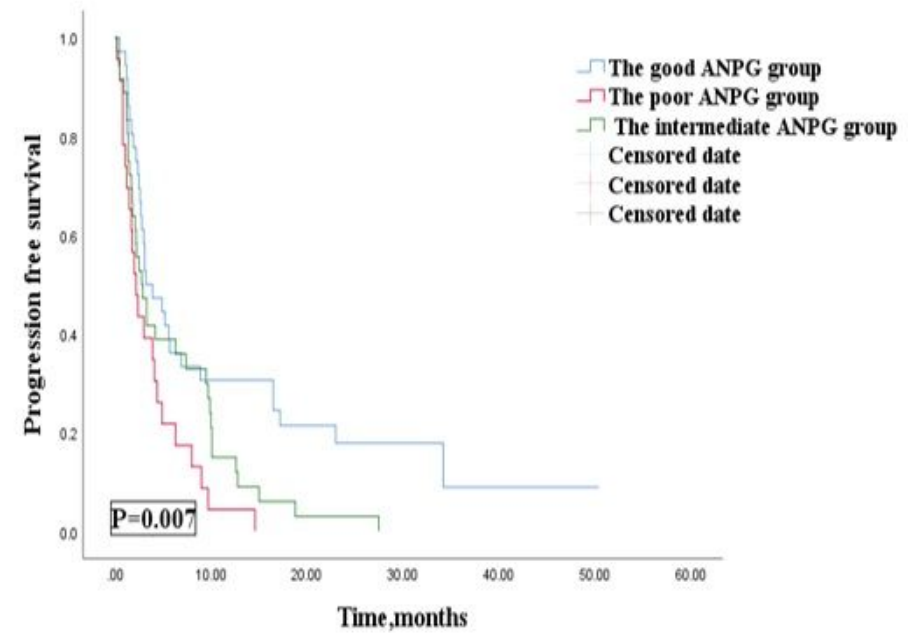

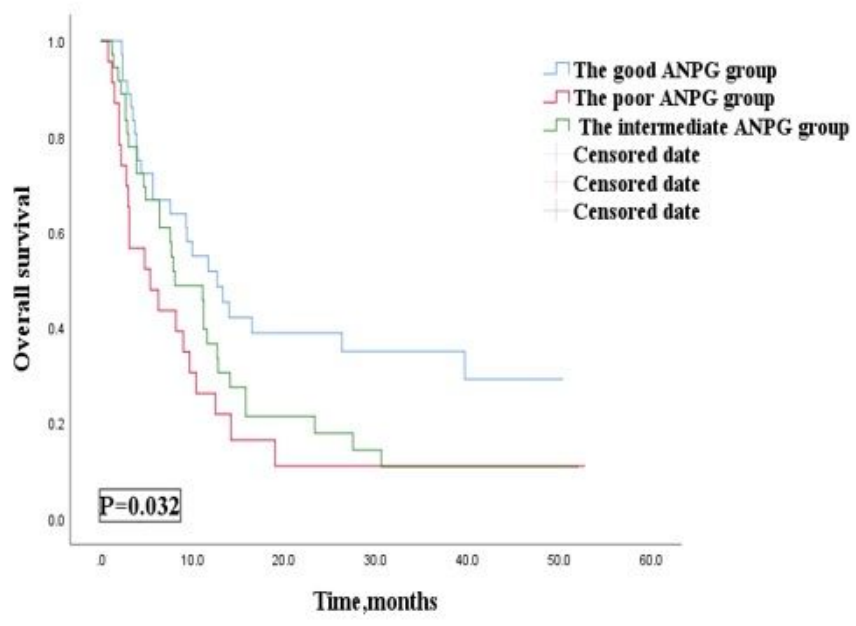

Figure 5

PFS (a) and (b) OS of AGC patients treated with ICls combined without chemotherapy, receiving PD-1 inhibitor cohort. 